OPEN ACCESS

Edited by:

Carlos Alberto Moreira-Filho,

University of São Paulo, Brazil

Reviewed by:

Fernando Porcelli,

University of Tuscia, Italy

Oleksandr Gryshkov,

Leibniz University Hannover, Germany

*Correspondence:

Florence Husson

florence.husson@agrosupdijon.fr

Specialty section:

This article was submitted to

Microbiotechnology,

a section of the journal

Frontiers in Microbiology

Received: 03 February 2020

Accepted: 20 July 2020

Published: 07 August 2020

Citation:

Nguyen TD, Guyot S, Pénicaud C, Passot $S$, Sandt $C$, Fonseca $F$,

Saurel $R$ and Husson F (2020)

Highlighting Protective Effect

of Encapsulation on Yeast Cell

Response to Dehydration Using

Synchrotron Infrared

Microspectroscopy at the Single-Cell

Level. Front. Microbiol. 11:1887.

doi: 10.3389/fmicb.2020.01887

\section{Highlighting Protective Effect of Encapsulation on Yeast Cell Response to Dehydration Using Synchrotron Infrared Microspectroscopy at the Single-Cell Level}

\author{
Thanh Dat Nguyen ${ }^{1}$, Stéphane Guyot ${ }^{1}$, Caroline Pénicaud ${ }^{2}$, Stéphanie Passot ${ }^{2}$, \\ Christophe Sandt ${ }^{3}$, Fernanda Fonseca ${ }^{2}$, Rémi Saurel ${ }^{1}$ and Florence Husson ${ }^{1 *}$ \\ 1 UMR PAM A 02.102, AgroSup Dijon, Université Bourgogne Franche-Comté, Dijon, France, ${ }^{2}$ INRAE, AgroParisTech, \\ Université Paris-Saclay, Thiverval-Grignon, France, ${ }^{3}$ SMIS Beamline, Synchrotron Soleil, Saint-Aubin, France
}

In the present paper, the Layer by Layer (LbL) method using $\beta$-lactoglobulin and sodium alginate was performed to individually encapsulate Saccharomyces cerevisiae cells in microorganized shells in order to protect them against stresses during dehydration. Higher survival $(\sim 1 \mathrm{log})$ for encapsulated yeast cells was effectively observed after air dehydration at $45^{\circ} \mathrm{C}$. For the first time, the potentiality of Synchrotron-Fourier Transform InfraRed microspectroscopy (S-FTIR) was used at the single-cell level in order to analyze the contribution of the biochemical composition of non-encapsulated vs. encapsulated cells in response to dehydration. The microspectroscopy measurements clearly differentiated between non-encapsulated and encapsulated yeast cells in the amide band region. In the spectral region specific to lipids, the S-FTIR results indicated probably the decrease in membrane fluidity of yeast after dehydration without significant distinction between the two samples. These data suggested minor apparent chemical changes in cell attributable to the LbL system upon dehydration. More insights are expected regarding the lower mortality among encapsulated cells. Indeed the hypothesis that the biopolymeric layers could induce less damage in cell by affecting the transfer kinetics during dehydration-rehydration cycle, should be verified in further work.

Keywords: yeast, encapsulation, dehydration, response, synchrotron FTIR

\section{INTRODUCTION}

Saccharomyces cerevisiae is an eukaryotic model organism widely used in many technological applications in food industries and in biofuel production. Before use, yeast end-production requires long-term stabilization processes preserving the viability of cells and maintaining their functionality. The main method used to preserve yeast is dehydration. However, during this process, cells are subjected to several stresses such as mechanical, hydric, thermal and oxidative stresses, and inducing cell death (Beker and Rapoport, 1987; Fu and Chen, 2011). Many previous 
studies have identified the plasma membrane as one of the main targets of cell injury associated to hydric disturbance in cell environment (Guyot et al., 2006; Simonin et al., 2007; Dupont et al., 2011; Penicaud et al., 2014; Câmara et al., 2019). In particular, in our previous study (Nguyen et al., 2017), synchrotron infrared spectroscopy revealed biochemical modifications during dehydration/rehydration processes of S. cerevisiae related to membrane fluidity. The cell wall, cytoplasmic membrane, nucleoplasm, and vacuoles may be irreversibly destroyed during dehydration, as reported elsewhere (Beker and Rapoport, 1987). On the other hand, dehydration in aerobic conditions increases the contact between cell surfaces and air, thus inducing the accumulation of reactive oxygen species (Gamero-Sandemetrio et al., 2014). Another previous works have shown that cell oxidation level increased significantly during airdrying (Pereira de Jusus et al., 2003; Garre et al., 2010). Oxidation phenomena cause damage to cell proteins, lipids, and nucleic acids (França et al., 2007) with severe consequences on the overall metabolism (Hansen et al., 2006).

Otherwise, yeast survival can be improved by using encapsulation methods. Among microencapsulation methods, the layer-by-layer (LbL) self-assembly technique have demonstrated particular interest to control cell viability and functionality (Kiprono et al., 2018). The LbL system is built by means of electrostatic attraction between oppositely charged polyelectrolytes forming successive layers deposited around the active core (Guzmán et al., 2017). This technique offers several advantages such as control over the required multilayer thickness (the wall thickness of capsules can be tailored in the $\mathrm{nm}-\mu \mathrm{m}$ range by adjusting the counter-ions, polyelectrolyte concentration, and $\mathrm{pH}$ ), a broad selection of shell materials among several types of synthetic/natural charged colloids, the simplicity of the LbL process and equipment, and good biocompatibility and biodegradability of most of the polyelectrolytes (de Villiers et al., 2011; Guzmán et al., 2017). Moreover, the shell produced by this method is able to enhance cell resistance to external stresses such as chemical stress, heating, malnutrition or enzymatic action, and to control cell division (Hong et al., 2013; Anselmo et al., 2016). Recently, the LbL encapsulation method was successfully applied to $S$. cerevisiae cells by our group and others (Nguyen et al., 2015; Kim et al., 2016; Nguyen, 2016; Moon et al., 2020). In our previous work (Nguyen et al., 2015), the protection of yeast cells against freezing and some chemical stresses by using a multilayer system based on $\beta$-lactoglobulin and alginate has been evidenced. In this refered work, Fourier-transform infrared (FTIR) spectroscopy was used to demonstrate that the LbL biopolymeric system did not affect the cell wall structure and preserve cell functionality.

Fourier-transform infrared spectroscopy is a powerful technique that reveals information on functional groups or bonds in biochemical components such as proteins, lipids, nucleic acids, and carbohydrates of the whole cell, cell wall and membranes. Compared to classical FTIR spectroscopy systems, synchrotron radiation infrared beam source offers 100-1000 times higher brightness than that of a Globar IR source (Miller and Dumas, 2006). This powerful technique is crucial to examine very small samples, opening up investigation of biochemical composition at the single-cell level and observation of the heterogeneity of cellular behavior affected by surrounding conditions. The potential of synchrotron FTIR (S-FTIR) microspectroscopy for imaging and spatially resolving biochemical analyses at the single-cell scale was demonstrated in previous works. Saulou et al. (2010, 2013) assessed the changes in S. cerevisiae and Escherichia coli after exposure to nano-silver coating and free ionic silver, respectively. By simultaneously acquiring information on the biochemical and physiological properties of Lactobacillus delbrueckii cells, Passot et al. (2015) were able to assess relevant spectral biomarkers of the cryotolerance of lactic acid bacteria. Moreover, this technique provides an opportunity to examine physiological and biochemical changes in yeast cells during dehydration in order to identify more precisely the molecular biomarkers associated to stress (Nguyen et al., 2015; Câmara et al., 2019).

In the present study, S. cerevisiae yeast cells were individually encapsulated by using the same LbL method as proposed in our previous work (Nguyen et al., 2015) in order to improve cell survival during a dehydration process. The protective effect of the biopolymeric capsule using $\beta$-lactoglobulin and sodium alginate as natural polyelectrolytes, was evaluated by means of cell survival measurements. In addition, the potential of S-FTIR method was evaluated in terms of analyzing the biochemical modifications of $S$. cerevisiae upon dehydration at the singlecell level.

\section{EXPERIMENTAL}

\section{Yeast Strain and Materials}

The yeast strain S. cerevisiae BY4742 (MATQ his $3 \Delta 1$ leu $\Delta 0$ lys $2 \Delta 0$ ura3 $\Delta 0$ ) was provided by Euroscarf (Frankfurt, Germany). Glucose, potassium acetate, sodium acetate, purified $\beta$-lactoglobulin ( $\beta \lg ,>90 \%$ purity), and L-cystein were all obtained from Sigma-Aldrich (Saint-Quentin Fallavier, France). Yeast extract and Agar were obtained from AES laboratory (Bruz, France). Peptone was obtained from Biokar diagnostics (Beauvais, France). Potassium dihydrogen phosphate $\left(\mathrm{KH}_{2} \mathrm{PO}_{4}\right)$ was obtained from Prolabo (Leuven, Belgium). Sodium alginate (Alg) was obtained from Fisher Scientific (Strasbourg, France). Alg was used after purification and freeze-drying as indicated in our previous paper (Nguyen et al., 2015). The intrinsic viscosity $(\eta)$ of alginate measured by capillary viscosimetry in $0.1 \mathrm{M} \mathrm{NaCl}$ at $20^{\circ} \mathrm{C}$ before and after purification was 554 and $485 \mathrm{~mL} / \mathrm{g}$, respectively.

\section{Culture Conditions}

Stored yeast cells were grown with an initial $\mathrm{OD}_{600}$ of 0.2 in $50 \mathrm{~mL}$ of a medium containing $30 \mathrm{~g} / \mathrm{L}$ Glucose, $30 \mathrm{~g} / \mathrm{L}$ Yeast extract, $0.6 \mathrm{~g} / \mathrm{L} \mathrm{KH}_{2} \mathrm{PO}_{4}$, and $0.6 \mathrm{~g} / \mathrm{L} \mathrm{L}$-Cysteine for pre-culture and culture. It was prepared in $250 \mathrm{~mL}$ battled Erlenmeyer flasks and shaken in an incubator at $140 \mathrm{rpm}$ and $30^{\circ} \mathrm{C}$ for $24 \mathrm{~h}$. The cells in the stationary phase were recovered by centrifugation, and were then washed twice with acetate buffer at $\mathrm{pH} 3.8$ before use. All microbiological experiments were carried out in triplicate from independent pre-cultures. 


\section{Encapsulation Procedure}

Yeast cells were encapsulated as described in our previous study (Nguyen et al., 2015). The cells were suspended in acetate buffer at $\mathrm{pH}$ 3.8. The $\beta$-lactoglobulin $(\beta \mathrm{lg})$ and sodium alginate (Alg) solutions were prepared at $0.1 \%(\mathrm{v} / \mathrm{v})$ and $0.01 \%(\mathrm{v} / \mathrm{v})$ concentrations, respectively. The cells were first incubated with the $\beta$ lg solution, then the Alg solution, and finally the $\beta \lg$ solution. It means that the cells were encapsulated with three layers of biopolymers as it has been previously evidenced (Nguyen et al., 2015). In this previous work, the thickness of the three layers was evaluated in the range of 140 to $190 \mathrm{~nm}$. The cell suspension at a final cellular concentration of $4.10^{7}$ cells $/ \mathrm{mL}$ was maintained under low stirring for $20 \mathrm{~min}$ at room temperature for complete adsorption. The polyelectrolytes which were not adsorbed were removed by washing twice with an acetate buffer between steps. At each step, the yeast cells were separated from the supernatant by centrifugation at $2000 \times g$ for $3 \mathrm{~min}$.

\section{Dehydration Process}

Yeast cells were dehydrated at $45^{\circ} \mathrm{C}$ following a previously described process (Lemetais et al., 2012). The specific dehydration chamber consisted of an airtight plastic box with controlled relative humidity. A saturated salt solution of $\mathrm{CH}_{3} \mathrm{COOK}$ was used to control the relative humidity in the chamber at $23 \%$. Samples were placed on a rack above the salt solution and the area of exposure was kept as large as possible in order to allow free diffusion of water. The chamber was maintained at $45^{\circ} \mathrm{C}$ and ventilated to increase mass transfer for $1 \mathrm{~h}$. The conservation time before experiments lasted about $24 \mathrm{~h}$, and the samples were kept in the chamber at $23 \%$ relative humidity at $25^{\circ} \mathrm{C}$.

\section{Yeast Survival}

The yeast survival was investigated via a cell cultivability test using the Colony-Forming Unit (CFU) method. For dehydrated yeast, the cells were rapidly rehydrated in an acetate buffer. Decimal dilutions of samples (hydrated and dehydrated/rehydrated cells) were plated in YPDA medium containing $20 \mathrm{~g} / \mathrm{L}$ Glucose, $20 \mathrm{~g} / \mathrm{L}$ Peptone, $10 \mathrm{~g} / \mathrm{L}$ Yeast extract, and $16 \mathrm{~g} / \mathrm{L}$ Agar. CFUs were counted after incubation for $36 \mathrm{~h}$ at $30^{\circ} \mathrm{C}$. All of the experiments were carried out in triplicate from independent pre-cultures and cultures.

\section{Synchrotron FTIR Microspectroscopy}

Synchrotron infrared microspectroscopy was performed at the SMIS beamline at the SOLEIL Synchrotron Facility (Saint-Aubin, France). The beamline is equipped with a Thermo Scientific Continuum infrared microscope coupled with a Thermo Scientific Nicolet 5700 spectrometer. The S-FTIR measurement was performed in transmission mode using $\mathrm{ZnSe}$ windows with a similar protocol as previously described by Nguyen et al. (2017). As yeast cells were around $5 \mu \mathrm{m}$ in diameter, the aperture was adjusted at $5 \times 5 \mu \mathrm{m}^{2}$ in order to collect the infrared signal at single cell level. The sample preparation and the experimental steps, reported in Figure 1, followed similar procedures as those described in our previous paper (Nguyen et al., 2017).
For infrared spectra acquisition, $2 \mu \mathrm{L}$ of hydrated cells (encapsulated and non-encapsulated cells) were directly deposited on the ZnSe window. Dehydrated cells (encapsulated and non-encapsulated), which were previously dehydrated in a dedicated chamber at $23 \%$ relative humidity, were rapidly rehydrated in an acetate buffer and then $2 \mu \mathrm{L}$ of dehydrated/rehydrated cells were deposited on the $\mathrm{ZnSe}$ window. Samples remained on the $\mathrm{ZnSe}$ window at room temperature for $15 \mathrm{~min}$ before spectral acquisition. The room temperature was $25^{\circ} \mathrm{C}$ and relative humidity was $25 \%$ (measured by Radiospare RS1364 Humidity-Temperature Meter). Individual spectra were acquired at $4 \mathrm{~cm}^{-1}$ spectral resolution, with 256 scans encompassing the mid-infrared region from 4000 to $800 \mathrm{~cm}^{-1}$. The high spatial resolution was obtained without compromising the quality of the infrared signal thanks to the synchrotron infrared radiation. For each condition tested, analyses were carried out on around 20 to 25 individual cells via a map (Figure 2) using the OMNIC software (Thermo Fisher Scientific, Madison, WI, United States).

\section{Statistical Analysis}

The analysis of the S-FTIR data was performed using the Unscrambler software (version 10.2, CAMO Process AS, Oslo, Norway). The analysis of the S-FTIR data was performed over four spectral regions (Figure 2):

(i) $\mathrm{S} 1\left(3010-2800 \mathrm{~cm}^{-1}\right)$ : the lipid region, exhibiting the $\mathrm{C}-\mathrm{H}$ stretching vibration of the $\mathrm{CH}_{3}$ and $\mathrm{CH}_{2}$ functional groups. The region is dominated by the spectral characteristics of fatty acid chains of the various phospholipid membranes and by some amino side-chain vibrations.

(ii) S2 $\left(1800-1500 \mathrm{~cm}^{-1}\right)$ : the protein region dominated by the protein conformation-sensitive amide I and amide II bands.

(iii) S3 (3650-2800 $\left.\mathrm{cm}^{-1}\right)$ : this large region exhibits the $\mathrm{O}-\mathrm{H}$ stretching vibrations in carbohydrates, the stretching vibrations of $\mathrm{N}-\mathrm{H}$ from proteins, and $\mathrm{C}-\mathrm{H}$ stretching vibrations of methyl and methylene groups ( $\mathrm{S} 1$ region).

(iv) $\mathrm{S} 4\left(1800-950 \mathrm{~cm}^{-1}\right)$ : the large $\mathrm{S} 4$ region is dominated by the protein amide bands ( $\mathrm{S} 2$ region), by the mannans and glucans $\mathrm{C}-\mathrm{O}-\mathrm{H}$ and $\mathrm{C}-\mathrm{O}-\mathrm{C}$ vibrations, the $\mathrm{P}=\mathrm{O}$ from phosphates in nucleic acids, and the $\mathrm{C}-\mathrm{H}$ bending modes from lipids.

The raw spectra were pretreated as previously described (Passot et al., 2015). The raw spectra were first baseline-corrected by subtracting a linear baseline and then normalized using the Unit Vector Normalization of the Unscrambler software. In order to investigate membrane fluidity, the second derivatives of spectra obtained in the spectral region from $2900-2830 \mathrm{~cm}^{-1}$ (exhibiting the symmetric of C-H stretching vibration of methyl and methylene groups) were calculated (Savitsky-Golay, order 3, 7-point smoothing factor), followed by normalization using unit vector normalization.

After pre-processing, the data were analyzed by the unsupervised principal component analysis (PCA) method so that the natural variation pattern in the data could be studied. 


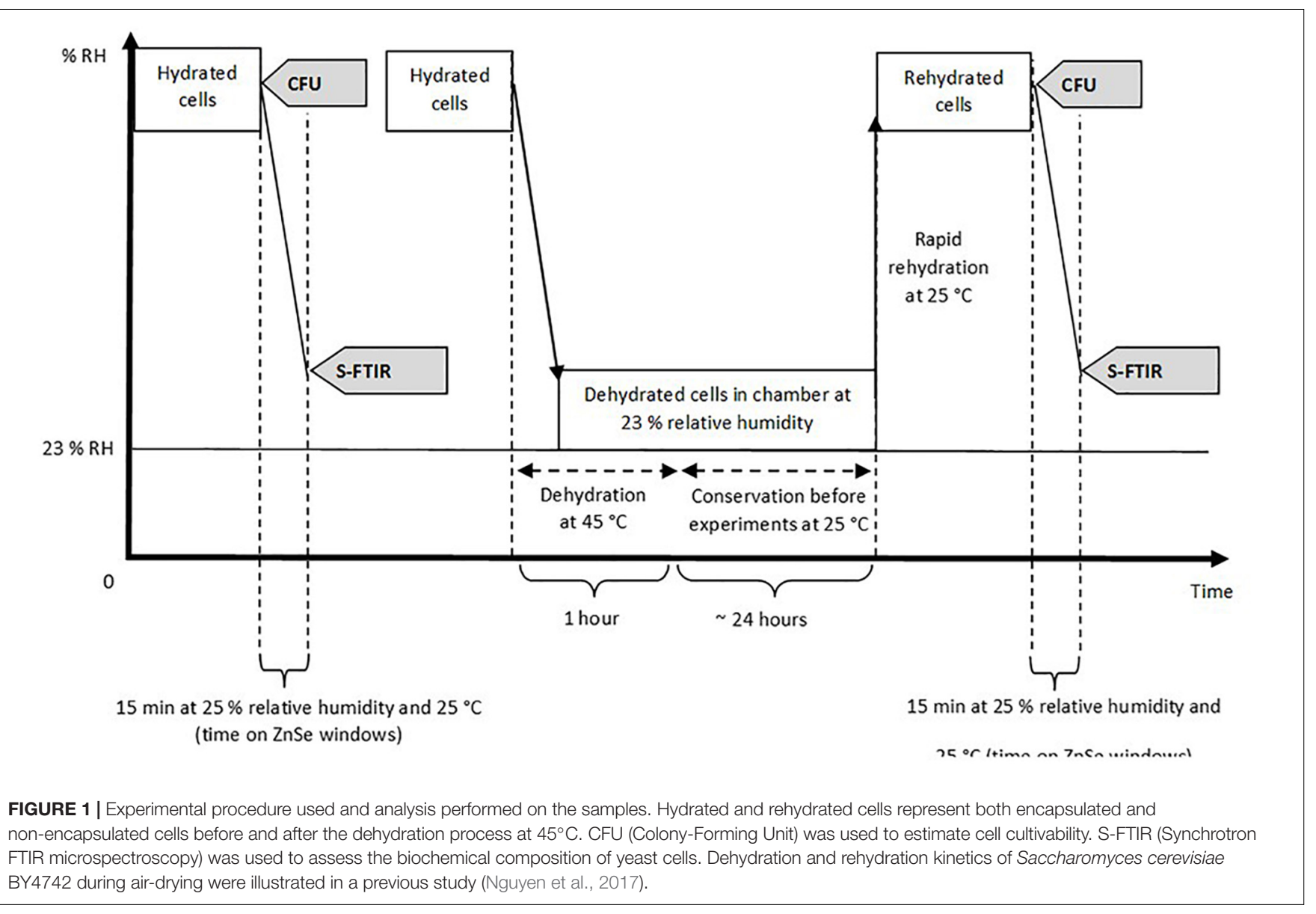

The PCA was carried out on mean centered data using the singular value decomposition algorithm and leverage validation method. 7 principal components were computed and the optimal number of components was found to be 3 or 4 in all analyses. Outliers were eliminated in a first round of PCA using the 95\% confidence Hotelling T2 ellipse.

The score plots show the projection of each spectrum onto the space defined by the corresponding principal components. The loading plots of principal components relate the behavior of the score plots to the spectral modifications in the sample such as shifts in band position, increase or decrease in absorption band intensities. These variations can, in turn, be related to biochemical changes within the individual groups.

\section{RESULTS AND DISCUSSION}

\section{Yeast Survival and Induced Biochemical Modifications}

Saccharomyces cerevisiae cells encapsulated or non-encapsulated were dehydrated at $45^{\circ} \mathrm{C}$. Yeast survival was investigated by estimating cell cultivability. The cell cultivability of encapsulated and non-encapsulated yeast was evaluated before and after dehydration at $45^{\circ} \mathrm{C}$ (Table 1). Results exposed in Table $\mathbf{1}$ indicate statistical contrasts between samples at the $95 \%$ confidence level. Before dehydration at $45^{\circ} \mathrm{C}$, no significant differences $(p<0.05)$ in the logarithm of CFU per $\mathrm{mL}$ between encapsulated and non-encapsulated cells indicated that encapsulation conditions did not affect yeast cultivability. Authors have previously demonstrated that $S$. cerevisiae cells preserved their metabolic activities and were able to divide after encapsulation process using LbL method (Diaspro et al., 2002; Drachuk et al., 2012).

The results showed a decrease in the survival of both encapsulated and non-encapsulated yeast cells after dehydration, indicating the destructive effect of this process. The decrease in cell survival due to dehydration has been historically demonstrated in the literature (Morgan et al., 2006; Dupont et al., 2011; Fu and Chen, 2011; Lemetais et al., 2012). However, the decrease in encapsulated cells $(2 \log )$ was lower than that in non-encapsulated cells $(3 \mathrm{log})$. The shell therefore provided a protection to yeast during dehydration. The protective effect of encapsulation using the $\mathrm{LbL}$ method on yeast survival to dehydration caused by freezing and freeze-drying has been elsewhere demonstrated (Thomas et al., 2014; Nguyen et al., 2015). To the best of our knowledge, this is the first time that the protection afforded by biopolymer shells against dehydration in air-drying at $45^{\circ} \mathrm{C}$ has been reported in yeast.

The presence of biopolymers on yeast surface could induce biochemical modifications of cells. Consequently, encapsulated 
A

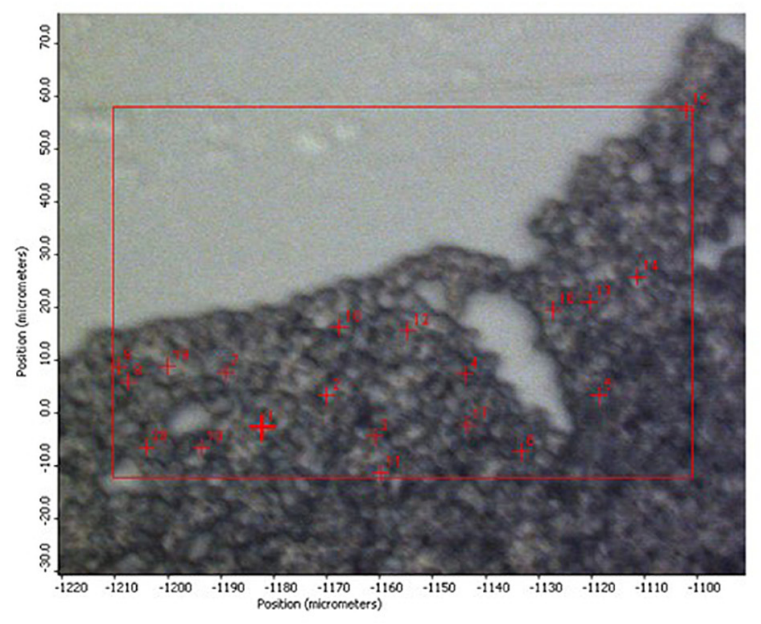

B

C
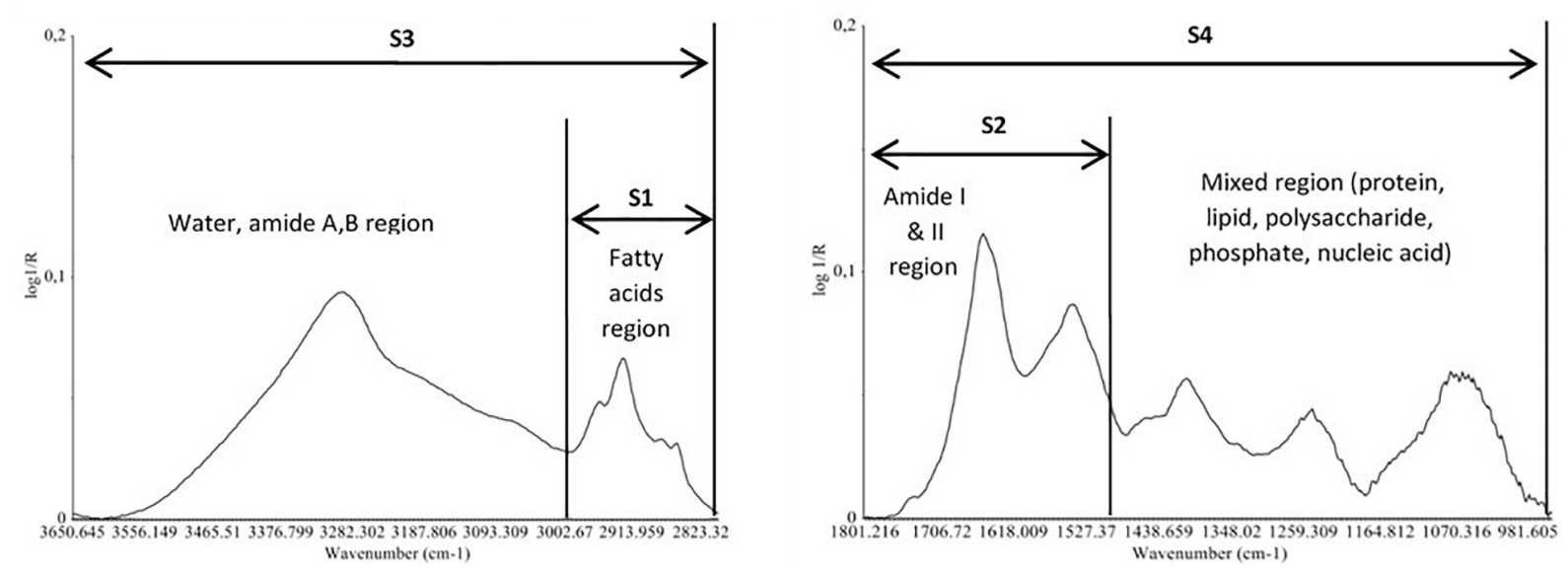

FIGURE 2 | Map of 20 randomly selected individual cells for infrared spectra acquisition (A). Representative corrected FTIR spectra of an individual cell of Saccharomyces cerevisae strain (non-encapsulated cell before the dehydration process) in the four spectral regions (S1, S2, S3, and S4) used for data analysis $(B, C)$.

and non-encapsulated yeast cells were analyzed by S-FITR in order to identify biochemical differences. The biochemical characterization of individual cells was expected to help to better understand the higher survival of encapsulated compared to non-encapsulated yeast after a dehydration process. In our

TABLE 1 | Cultivability counts (log CFU/mL) of Saccharomyces cerevisiae cells determined before and after dehydration.

\section{$\log$ CFU/mL}

Non-encapsulated cells

\section{Before dehydration}

$7.32 \pm 0.03^{a}$

$7.17 \pm 0.06^{\mathrm{a}}$
After dehydration

$3.96 \pm 0.41^{\mathrm{b}}$

$5.09 \pm 0.35^{\mathrm{c}}$
Encapsulated cells

Values with the same superscript letters are not significantly different at the $95 \%$ confidence level. previous study, it was demonstrated that the average shell thickness of three layers $(\beta \mathrm{lg} / \mathrm{Alg} / \beta \mathrm{lg})$ was approximately $140-$ $190 \mathrm{~nm}$ (Nguyen et al., 2015).

Principal component analysis was used to identify specific regions of the S-FTIR spectra that contribute to the discrimination of the fresh yeast cells (both encapsulated and non-encapsulated). PCA was performed in all the spectral regions between 4000 and $950 \mathrm{~cm}^{-1}$ ). Only regions S1 (3010$\left.2800 \mathrm{~cm}^{-1}\right)$ and S2 (1800-1500 $\left.\mathrm{cm}^{-1}\right)$ of the S-FTIR spectra, involving information about lipids and proteins, contributed to the discrimination of the fresh yeast cells and were further studied. The first component (PC1) vs. the second component (PC2) score plots and the loading plots are presented in Figure 3.

The $\mathrm{S} 1$ region $\left(3010-2800 \mathrm{~cm}^{-1}\right)$ is dominated by the signal of the $\mathrm{C}-\mathrm{H}$ stretching vibrations of $\mathrm{CH}_{3}$ and $\mathrm{CH}_{2}$ functional groups, corresponding to the fatty acid chains of the various membrane 


\section{S1 region}

A

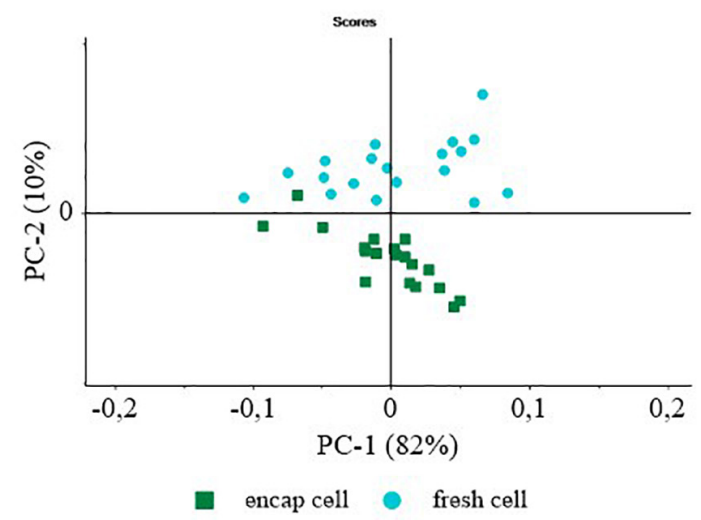

C

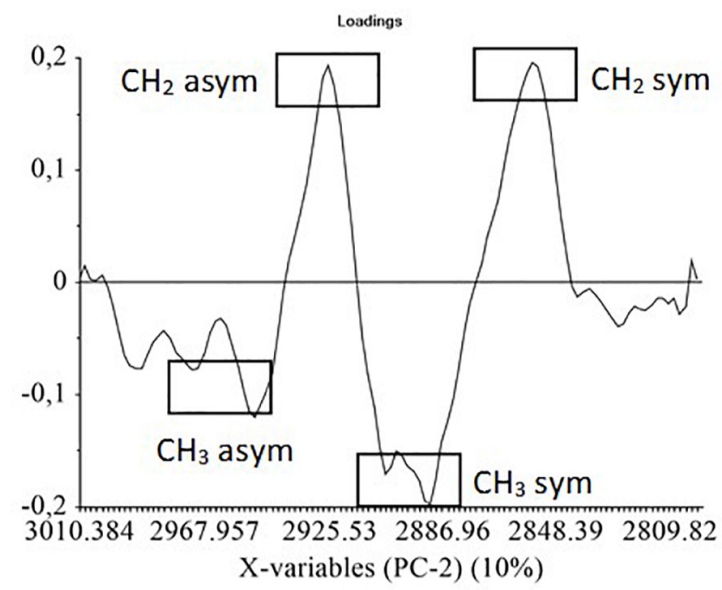

S2 region

B

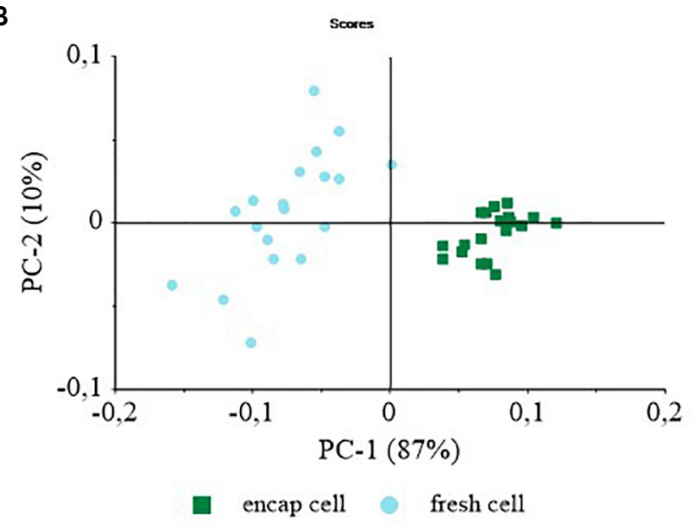

D

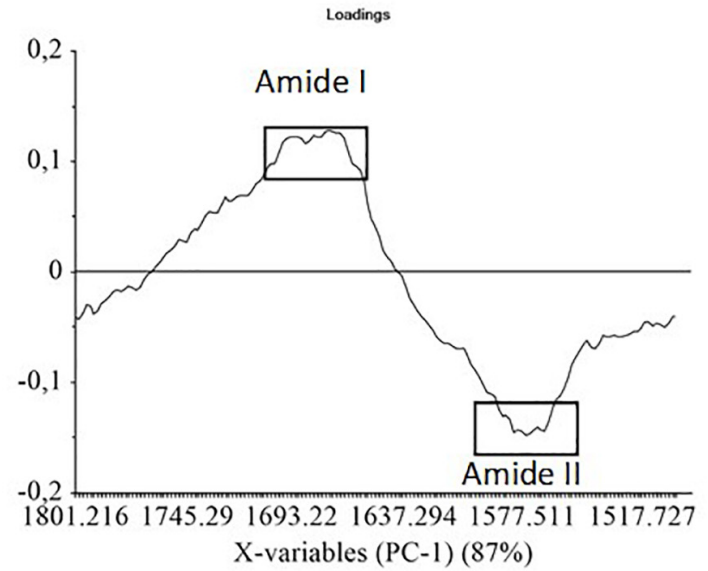

FIGURE 3 | Principal component analysis of S-FTIR spectra obtained for encapsulated and non-encapsulated fresh cells in two spectral regions S1 and S2. PCA score plots (A, B); and PCA loading plots (C, D) of PC1 vs. PC2. The score plots show the discrimination between samples. The loading plots indicate the spectral variance within and between samples.

phospholipids and to some amino side-chain vibrations from proteins (Burattini et al., 2008; Passot et al., 2015). Although PC1 captured the highest spectral variability (82\%), it appeared to be related to the cell dispersion within each sample (Figure 3A). This could be ascribed to differences in membrane composition of individual yeast cells.

Although the most important chemical heterogeneity within yeast populations was not related to encapsulation in this spectral region, the PCA score plots showed a near perfect cluster separation according to encapsulation along PC2 axis using 10\% of spectral variance.

Non-encapsulated cells (fresh cell) clustered on the positive part, whereas encapsulated cells (encap cell) clustered on the negative part of the PC2 axis (Figure 3A). In Figure 3C, positive peaks in the loading plot of PC2 corresponded to spectral features associated with the non-encapsulated cell population and appeared to be specifically correlated to the C-H stretching vibration of the $\mathrm{CH}_{2}$ methylene group (2925 and $2850 \mathrm{~cm}^{-1}$ ). The encapsulated cells were characterized by $\mathrm{CH}_{3}$ methyl groups (2960 and $2890 \mathrm{~cm}^{-1}$ ). It indicated that the $\mathrm{CH}_{2}: \mathrm{CH}_{3}$ ratio was different between these two populations. The higher methyl groups contribution observed in encapsulated yeast could be due to the presence of $\beta$-lactoglobulin in the microorganized shell although the presence of alginate should increase the contribution of methylene group.

Furthermore, another hypothesis is that the change of $\mathrm{CH}_{2}: \mathrm{CH}_{3}$ ratio could be the consequence of changes in membrane composition, in particular in lipid composition. Higher contribution of $\mathrm{CH}_{3}$ bands could be related to higher number of short-chain fatty acids. In contrast, higher contribution of $\mathrm{CH}_{2}$ bands could reflect the presence of longer and/or more saturated acyl chain (Ami et al., 2009; Saulou et al., 
2013). Such variation of the $\mathrm{CH}_{2}: \mathrm{CH}_{3}$ ratio could be related to the encapsulation process by generating acid stress and inducing change in membrane fluidity through membrane adaptation by the means of biochemical modifications. Yeast response to dehydration could depend on the length and saturation of fatty acid chains. In the study carried out by Passot et al. (2015), the authors reported that bacteria cells grown in a rich medium presented a higher content in $\mathrm{CH}_{3}$ groups assigned to lipid chains and a higher survival after dehydration by freezing. In the present work, a similar trend was found in terms of the relationship between higher number of short-chain fatty acids and higher survival after dehydration, as observed in the case of encapsulated yeast. Therefore, the membrane adaptation induced by the multilayer shells could led to a protective effect on yeast during dehydration process.

In the $\mathrm{S} 2$ region $\left(1800-1500 \mathrm{~cm}^{-1}\right)$, infrared spectral absorption exhibits the $\mathrm{C}=\mathrm{O}$ stretching of amide $\mathrm{I}, \mathrm{C}-\mathrm{N}$ stretching and $\mathrm{N}-\mathrm{H}$ bending of amide II. According to the PCA score plot, PC1 capturing $87 \%$ of spectral variability separated encapsulated cell (encap cell) from non-encapsulated cell (fresh cell) clusters (Figure 3B). Other principal components did not separate the two populations and carried information on the variability within the clusters, regardless of population considered. The most important chemical heterogeneity within yeast populations in this spectral region was therefore related to encapsulation. When considering $\mathrm{PC} 1$, the positive peaks of the amide I protein range were associated with nonencapsulated cell clusters, while the encapsulated cell population was characterized by the negative peaks of the amide II protein range (Figure 3D). This result evidenced a change in the amide I/amide II ratio between the two cell populations, thus suggesting that the secondary structure of protein in encapsulated cells was different from the secondary structure of protein in non-encapsulated cells. Different hypotheses can be put forward for explaining this result: (i) protein structure changes in existing proteins; (ii) expression of new proteins; (iii) proteins of the shell; or (iv) different dehydration kinetics when preparing the cells for FTIR. Furthermore, by analyzing second derivative of S-FTIR spectra in this specific region (data not shown) the denaturation of proteins was not observed following encapsulation. This result was also consistent with our previous work (Nguyen et al., 2015), showing that the electrostatic complexation between $\beta$-lactoglobulin and alginate only did not lead to modification in the secondary structure of protein. Thus, the amide band changes differentiating encapsulated and nonencapsulated cells, could probably be related to the changes in the $\mathrm{CH} 3: \mathrm{CH} 2$ ratio in the $\mathrm{S} 1$ region indicating the presence of $\beta$-lactoglobulin in the microorganized shell or the modification of cell protein content.

\section{Dehydration Induced Biochemical Modification in Yeast Cells}

The infrared spectra of individual encapsulated and nonencapsulated cells before (encapsulated cell and fresh cell) and after (dried encapsulated cell and dried cell) dehydration were monitored in two large regions, S3 (3650-2800 $\left.\mathrm{cm}^{-1}\right)$ and
S4 (1800-1500 $\left.\mathrm{cm}^{-1}\right)$, which contained information on the water/biomass ratio and on biomolecules, respectively. These results are reported in Figure 4.

The S3 region $\left(3650-2800 \mathrm{~cm}^{-1}\right)$ includes the contribution of $\mathrm{O}-\mathrm{H}$ stretching in carbohydrates around $3500-3400 \mathrm{~cm}^{-1}$, the $\mathrm{N}-\mathrm{H}$ stretching in proteins at $3300 \mathrm{~cm}^{-1}$, the amide II overtone around $3100 \mathrm{~cm}^{-1}$, the absorptions mainly assigned to $\mathrm{CH}_{3}$ and $\mathrm{CH}_{2}$ functional groups (asymmetric vibrations at $2960 \mathrm{~cm}^{-1}$ and $2925 \mathrm{~cm}^{-1}$; symmetric vibrations at $2870 \mathrm{~cm}^{-1}$, and $2855 \mathrm{~cm}^{-1}$; Burattini et al., 2008). In Figure 4A, the score plot showed the spectral variability along the PC1 axis within the groups. Dried yeast cell populations were separated from fresh yeast cell populations by PC1 with $89 \%$ of the spectral variance. Thus, PC1 revealed the effect of dehydration, regardless of whether the cells were encapsulated or not. According to the PC1 loading plot (Figure 4C), the negative peak at $3400 \mathrm{~cm}^{-1}$ associated with $\mathrm{O}-\mathrm{H}$ stretching vibration corresponded to the higher water content in the cell populations before dehydration that clustered on the negative part of the PC1 axis. The reduced $\mathrm{O}-\mathrm{H}$ vibration absorption was thus clearly related to the decreased water content in yeast, resulting in osmotic stress which affected cell cultivability negatively (Gervais et al., 1992; Beney et al., 2000; Lemetais et al., 2012). The higher contribution of proteins and fatty acid bands observed in dried cells could be due to the water/biomass ratios or simply due to the spectral normalization procedure.

The S4 region (1800-950 $\mathrm{cm}^{-1}$ ) carries the absorption peaks from proteins, lipids, nucleic acids, and cell wall polysaccharides (mannans and glucans; Burattini et al., 2008; Gautier et al., 2013; Passot et al., 2015). The PCA score plot (Figure 4B) showed a clear separation between fresh cell and dried cell populations along PC1 with $90 \%$ of the spectral variance. The fresh cells were found on the negative part while the dried cells were positioned on the positive part of the first principal component. Therefore, the spectral variability monitored by $\mathrm{PC} 1$ revealed the effect of dehydration in this spectral region. Encapsulated and nonencapsulated cells were also separated along PC1 axis showing that there was more organic matter in the encapsulated cells than in the non-encapsulated cells, even when dried.

According to the PC1 loading plot (Figure 4D), the negative peaks of amide I $\left(1660 \mathrm{~cm}^{-1}\right)$, polysaccharide $\left(1200-900 \mathrm{~cm}^{-1}\right)$, and phosphate $\left(1247 \mathrm{~cm}^{-1}\right)$ bands appeared to be associated with the fresh cells, while the dried cells were characterized by a higher contribution of amide II $\left(1575 \mathrm{~cm}^{-1}\right)$ and proteins and lipids (1500-1300 $\mathrm{cm}^{-1}$ ) bands. The discrimination between fresh and dried cells could therefore be ascribed to differences in secondary protein structure, RNA and cell wall composition. Ishida and Griffith reported a strong change in the amide I/amide II ratio for $\beta$-lactoglobulin in solution compared to dehydrated films (Ishida and Griffiths, 1993). This could explain the strong amide I/amide II changes at $1660 \mathrm{~cm}^{-1}$ and $1575 \mathrm{~cm}^{-1}$ in PC1 loadings. Differences in the intensity of proteins, lipids, and polysaccharides bands between hydrated and dehydrated cells could be due to the amount of water in samples.

principal component analysis results of two large regions S3 and S4 showed clearly differences in yeast response to dehydration. In order to observe more precisely the effect of the 


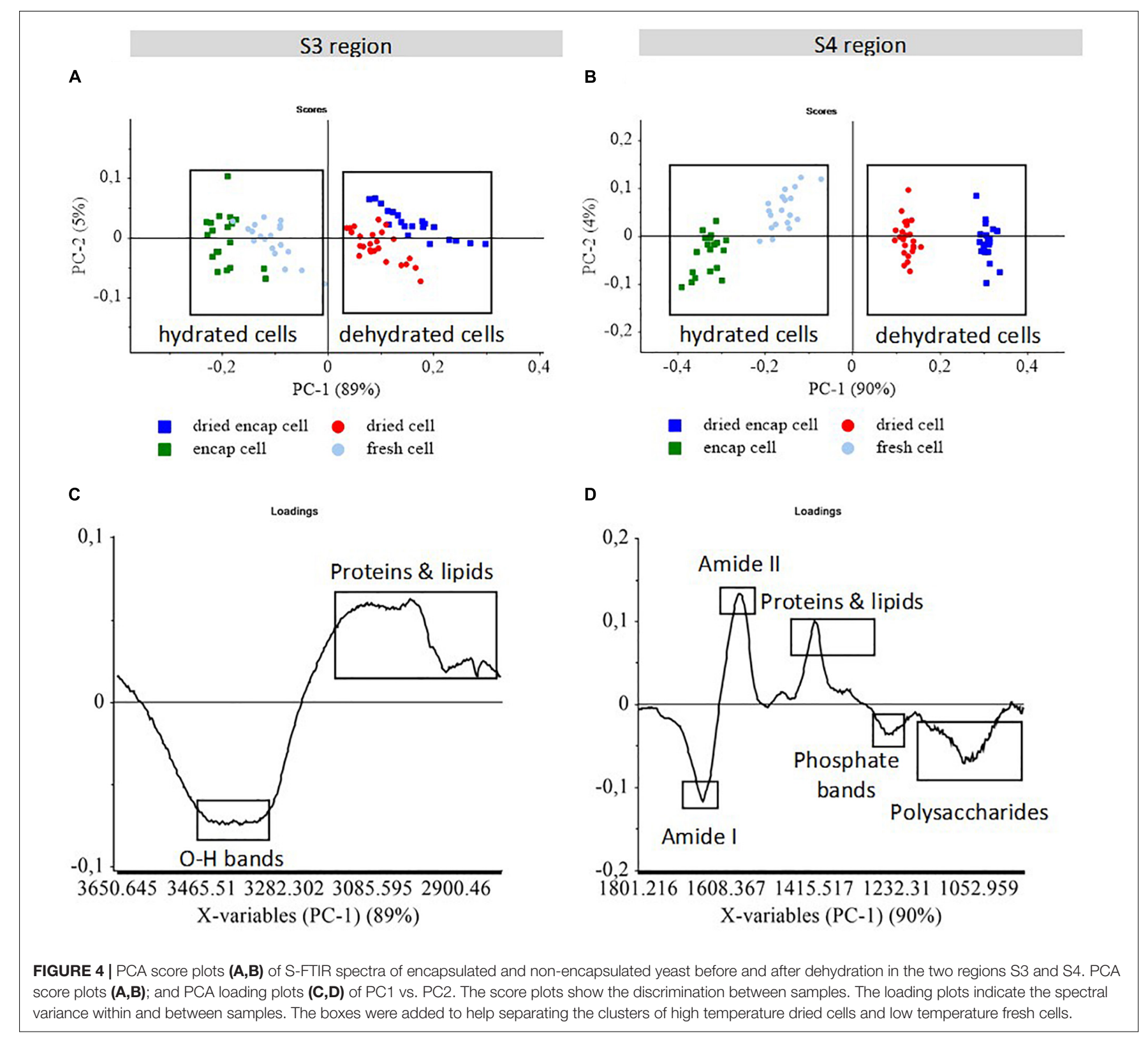

dehydration process on yeast composition, we analyzed the mean S-FTIR spectra of each population in the specific regions $\mathrm{S} 1$ and S2 containing information for lipids and proteins. The results were reported in Figures 5, 6.

Figure 5 presented the second derivative of mean spectra for encapsulated and non-encapsulated cells before and after the dehydration process at $45^{\circ} \mathrm{C}$ in the specific region (from 2900 to $2830 \mathrm{~cm}^{-1}$ ) containing the contribution of the symmetric $\mathrm{C}-\mathrm{H}$ stretching vibration of the $\mathrm{CH}_{2}$ and $\mathrm{CH}_{3}$ groups. After dehydration, the intensity of the $\mathrm{CH}_{3}$ symmetric stretching band at $2875 \mathrm{~cm}^{-1}$ increased relative to the methylene band. This indicates that the ratio of the number of methylene groups to that of methyl groups decreased in dried samples, as compared to hydrated samples (both encapsulated and nonencapsulated cells). The decrease in number of methylene groups could correspond to the reduction of the number of longchain fatty acids, which could originate from the degradation of lipid by hydrolysis or oxidation (Ami et al., 2009; Fuchs et al., 2011). This suggested changes in the lipid membrane during dehydration process. Burattini et al. (2008) reported the reduction of the $v_{\text {sym }}\left(\mathrm{CH}_{2}\right) / \nu_{\text {sym }}\left(\mathrm{CH}_{3}\right)$ intensity ratio, which can be attributed to the degradation of fatty acid chains by $\beta$-oxidation, in their study of autolysis in cells of the wine yeast S. cerevisiae (Burattini et al., 2008). Moreover, the difference in the $v_{\text {sym }}(\mathrm{CH} 2) / \nu_{\text {sym }}(\mathrm{CH} 3)$ intensity ratio of non-encapsulated cells before and after dehydration at $45^{\circ} \mathrm{C}$ seemed higher than that of encapsulated cells ( $\sim 30 \%$ higher). It means that the length of the fatty acid chains of non-encapsulated cells were more negatively affected by the dehydration process at $45^{\circ} \mathrm{C}$ than that of encapsulated cells. The presence of micro-organized 


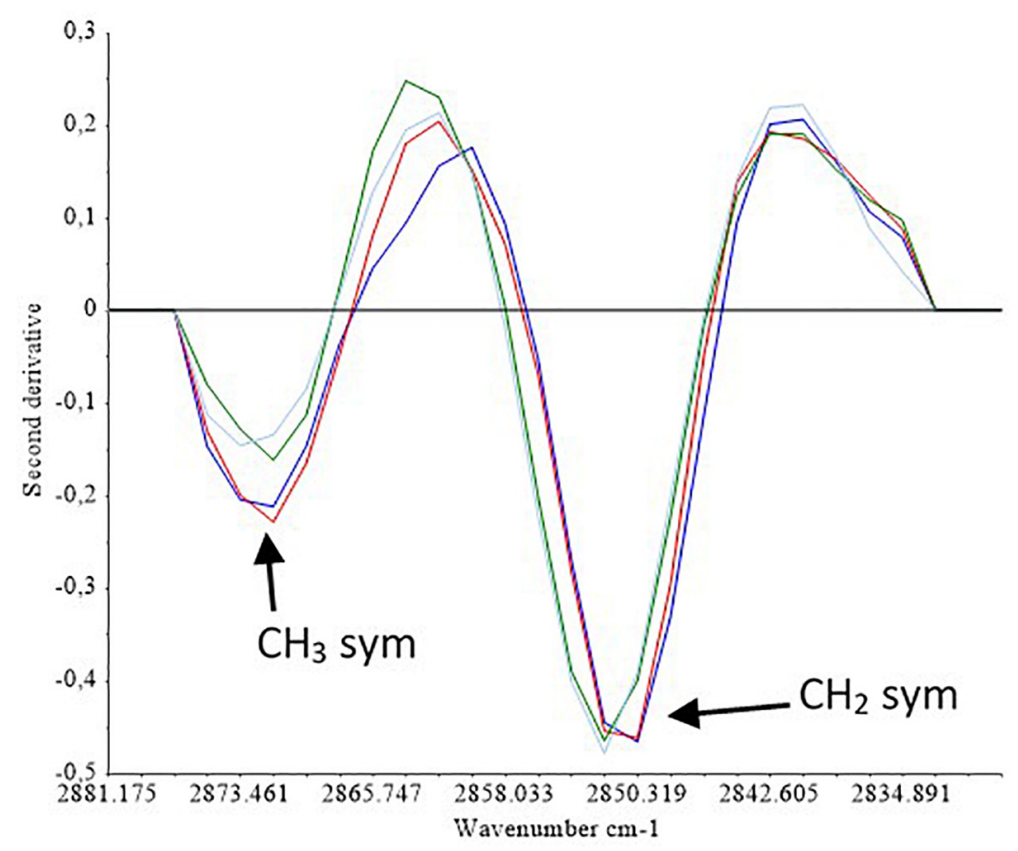

- dried encap cell dried cell encap cell fresh cell

FIGURE 5 | Second derivate of the spectra in the S1 region.

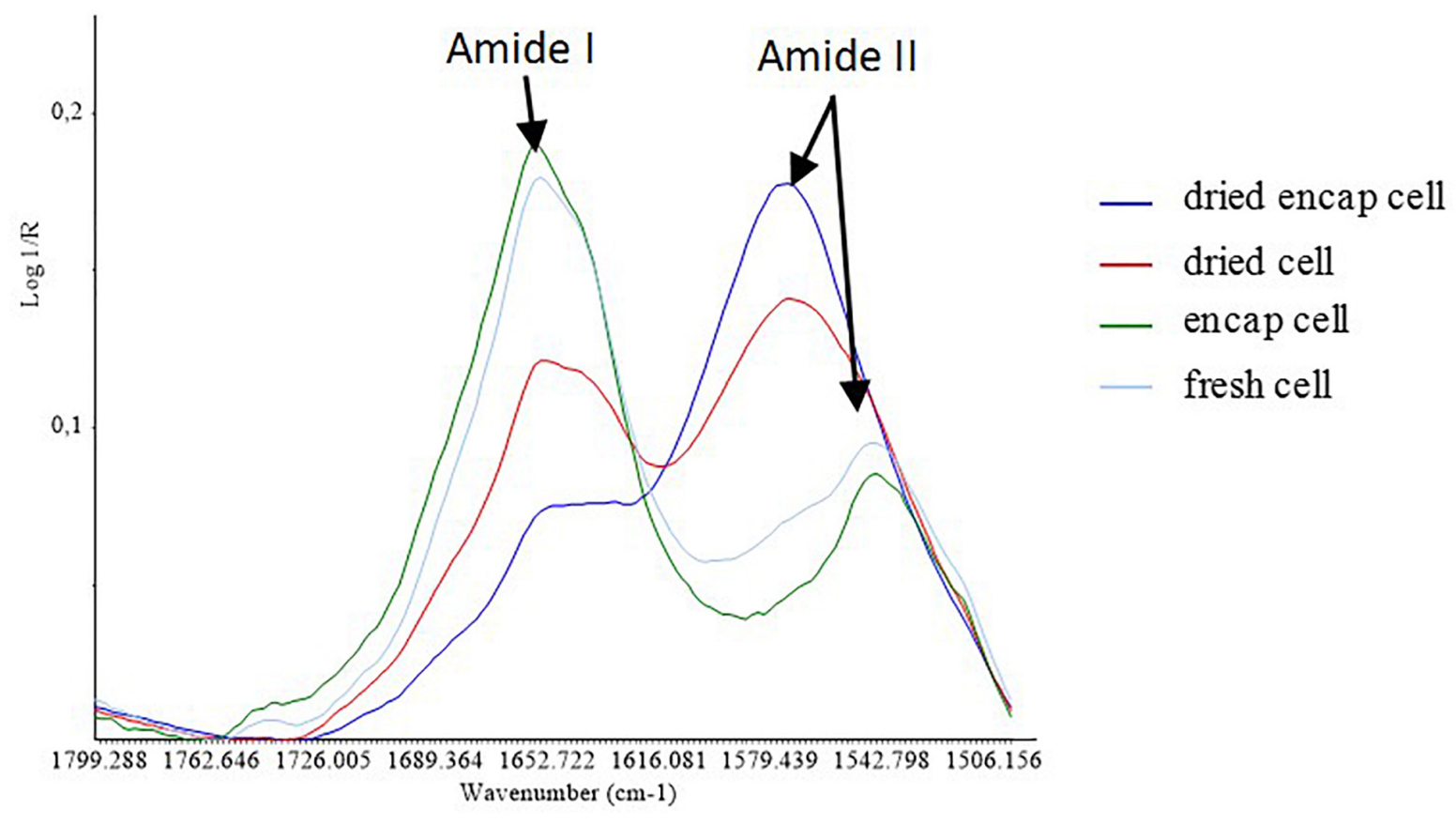

FIGURE 6 | Average spectra of the samples in the S2 region.

shells can therefore better preserve the lipid composition of yeast during dehydration.

Furthermore, dehydration can induce change in membrane fluidity and can be related to cell death. Some authors have reported that cell membranes became more rigid for water activity values from 0.88 to 0.37 during yeast dehydration at constant temperature (Simonin et al., 2008). The band position of symmetric C-H stretching vibration corresponding to $\mathrm{CH}_{2}$ groups was reported as indicator of membrane fluidity (AlvarezOrdóñez et al., 2010). In the Figure 5, a shift of the $\mathrm{CH}_{2}$ bands to a lower wavenumber is observed following dehydration, regardless of whether the cells were encapsulated or not. This could be 
associated with reduction of membrane fluidity. Passot et al. (2015) similarly found that freezing resulted in a downshift of the symmetric $\mathrm{C}-\mathrm{H}$ vibration of the $\mathrm{CH}_{2}$ methylene groups. Another study reported that the downshift of the symmetric $\mathrm{CH}_{2}$ stretching peak associated with cell death (Saulou et al., 2013). In the present work, the presence of micro-organized shells could not preserve membrane fluidity of yeast during dehydration. Furthermore, yeast survival has been reported to depend on the dehydration and rehydration kinetics. Authors reported that higher survival was observed when the dehydration/rehydration process was progressive (Lemetais et al., 2012). The presence of micro-organized shells on yeast could induce a protective effect by a physical effect. The shell could be a barrier that reduced the kinetics of water transfer during dehydration/rehydration cycle, leading to higher cell survival.

Focusing on the amide I and amide II protein region (Figure 6), the spectral profile of yeast after the dehydration process at $45^{\circ} \mathrm{C}$ was different from that of yeast before treatment. After dehydration, the intensity of amide I bands $\left(\sim 1660 \mathrm{~cm}^{-1}\right)$ decreased in both encapsulated and non-encapsulated cells. The amide I vibration is hardly affected by the nature of the side chain. It depends instead on the secondary structure of the backbone and presents strong bands at $1653 \mathrm{~cm}^{-1}$ and $1633 \mathrm{~cm}^{-1}$. These bands are described in the literature as being features of $\alpha$-helix and $\beta$-sheet structures (Oberg et al., 2004). No significant shift was observed for these bands suggesting limited effect in ordered secondary structure. Furthermore, our results showed the appearance of a peak at $1575 \mathrm{~cm}^{-1}$ after the dehydration process at high temperature in both encapsulated and non-encapsulated cells. Oberg et al. (2004) reported that amide II provides significant information and could be used alone for the prediction of protein secondary structure. The amide II bands are recognized in the main peak at $1550 \mathrm{~cm}^{-1}$ (Barth, 2007; Cavagna et al., 2010). However, the data regions from 1590 to $1500 \mathrm{~cm}^{-1}$ (Oberg et al., 2004; Movasaghi et al., 2008) or from 1480 to $1575 \mathrm{~cm}^{-1}$ (Kong and $\mathrm{Yu}, 2007$ ) have been described associated to amide II bands. The appearance of the peak at $1575 \mathrm{~cm}^{-1}$ might therefore be considered as a shift from the peak at $1550 \mathrm{~cm}^{-1}$ to the new one, linked to modifications in protein conformation. However, other chemical modifications cannot be excluded. Indeed, Palacios and JuárezLópez (2004) and Otero et al. (2014), have assessed by IR spectroscopy that peak at $1575 \mathrm{~cm}^{-1}$ corresponded to $\mathrm{Fe}$ (III) carboxylate and $\mathrm{Ca}$ (II) carboxylate, respectively, suggesting that such metallo-complexes could be formed during dehydration in our experimental conditions.

\section{CONCLUSION}

This study provided evidence for the application of the LbL encapsulation method on $S$. cerevisiae in order to protect

\section{REFERENCES}

Alvarez-Ordóñez, A., Halisch, J., and Prieto, M. (2010). Changes in Fourier transform infrared spectra of Salmonella enterica serovars Typhimurium and yeast cells against dehydration at high temperature and highlighted the mechanism impact of this process on yeast cells. Moreover, protective mechanism of microorganized shells on yeast responses was proposed. The lower $\mathrm{CH}_{2}: \mathrm{CH}_{3}$ ratio observed in lipid spectral region could be ascribed to the encapsulation process without clear differentiation between the presence of organic matter at the cell interface or modification of membrane chemical composition. During dehydration, encapsulated yeast presented a higher survival and a higher methyl group contribution. Alternatively to direct chemical modifications of the cell structure, the presence of hydrocolloids at the cell interface could be a barrier limiting stress due to water transfer upon dehydration-rehydration cycle. The coupled study of biochemical and physiological responses of cells following different kinetics of dehydration/rehydration would confirm the role of microorganized shells on yeast resistance to dehydration.

\section{DATA AVAILABILITY STATEMENT}

The datasets generated for this study are available on request to the corresponding author.

\section{AUTHOR CONTRIBUTIONS}

TN, RS, and FH contributed to the conception and design of the study. TN, SG, CP, SP, CS, FF, RS, and $\mathrm{FH}$ did all the experiments at Synchrotron Soleil. TN wrote the first draft of the manuscript. All authors contributed to manuscript revision, read and approved the submitted version.

\section{FUNDING}

This work was supported by the Conseil Régional de Bourgogne through the "plan d'actions régional pour l'innovation" (PARI) and the European Union through the PO FEDER-FSE Bourgogne 2014/2020 programs.

\section{ACKNOWLEDGMENTS}

We would like to thank the French national synchrotron facility SOLEIL (Gif sur Yvette, France) and the SMIS beamline (proposal no. 20140185) for their support in preparing the samples and in performing Synchrotron FTIR microspectroscopy. We would like to thank the UMR PAM that permitted to support the Ph.D. of the first author.

Enteritidis after adaptation to stressful growth conditions. Int. J. Food Microbiol. 142, 97-105. doi: 10.1016/j.ijfoodmicro.2010.06.008

Ami, D., Natalello, A., Schultz, T., Gatti-Lafranconi, P., Lotti, M., Doglia, S. M., et al. (2009). Effects of recombinant protein misfolding and aggregation on 
bacterial membranes. Biochim. Biophys. Acta ProteinsProteomics 1794, 263-269. doi: 10.1016/j.bbapap.2008.10.015

Anselmo, A. C., McHugh, K. J., Webster, J., Langer, R., and Jaklenec, A. (2016). Layer-by-layer encapsulation of probiotics for delivery to the microbiome. $A d v$. Mater. 28, 9486-9490. doi: 10.1002/adma.201603270

Barth, A. (2007). Infrared spectroscopy of proteins. Biochim. Biophys. Acta Bioenerget. 1767, 1073-1101.

Beker, M., and Rapoport, A. (1987). "Conservation of yeasts by dehydration," in Biotechnol. Methods, Vol. 35 (Berlin: Springer), 127-171. doi: 10.1007/ bfb0004428

Beney, L., Mart $ı$ ìnez, D. M. I, Marechal, P.-A., and Gervais, P. (2000). Influence of thermal and osmotic stresses on the viability of the yeast Saccharomyces cerevisiae. Int. J. Food Microbiol. 55, 275-279. doi: 10.1016/s0168-1605(00) 00203-8

Burattini, E., Cavagna, M., Dell'Anna, R., Malvezzi Campeggi, F., Monti, F., Rossi, F., et al. (2008). A FTIR microspectroscopy study of autolysis in cells of the wine yeast Saccharomyces cerevisiae. Vib. Spectrosc. 47, 139-147. doi: 10.1016/ j.vibspec.2008.04.007

Câmara, A., de, A., Maréchal, P. A., Tourdot-Maréchal, R., and Husson, F. (2019). Dehydration stress responses of yeasts Torulaspora delbrueckii, Metschnikovia pulcherrima, lacchancea thermotolerans: Effects of glutathione and trehalose biosynthesis. Food Microbiol. 79, 137-146. doi: 10.1016/j.fm.2018. 12.008

Cavagna, M., Dell'Anna, R., Monti, F., Rossi, F., and Torriani, S. (2010). Use of ATR-FTIR microspectroscopy to monitor autolysis of Saccharomyces cerevisiae cells in a base wine. J. Agric. Food Chem. 58, 39-45. doi: 10.1021/jf902 $369 \mathrm{~s}$

de Villiers, M. M., Otto, D. P., Strydom, S. J., and Lvov, Y. M. (2011). Introduction to nanocoatings produced by layer-by-layer (LbL) self-assembly. Adv. Drug Deliv. Rev. 63, 701-715. doi: 10.1016/j.addr.2011.05.011

Diaspro, A., Silvano, D., Krol, S., Cavalleri, O., and Gliozzi, A. (2002). Single living cell encapsulation in nano-organized polyelectrolyte shells. Langmuir 18, 5047-5050. doi: 10.1021/la025646e

Drachuk, I., Shchepelina, O., Lisunova, M., Harbaugh, S., Kelley-Loughnane, N., Stone, M., et al. (2012). pH-responsive layer-by-layer nanoshells for direct regulation of cell activity. ACS Nano 6, 4266-4278. doi: 10.1021/nn300 8355

Dupont, S., Beney, L., Ferreira, T., and Gervais, P. (2011). Nature of sterols affects plasma membrane behavior and yeast survival during dehydration. Biochim. Biophys. Acta Biomembr. 1808, 1520-1528. doi: 10.1016/j.bbamem.2010.11.012

França, M. B., Panek, A. D., and Eleutherio, E. C. A. (2007). Oxidative stress and its effects during dehydration. Comp. Biochem. Physiol. A Mol. Integr. Physiol. 146, 621-631. doi: 10.1016/j.cbpa.2006.02.030

Fu, N., and Chen, X. D. (2011). Towards a maximal cell survival in convective thermal drying processes. Food Res. Int. 44, 1127-1149. doi: 10.1016/j.foodres. 2011.03.053

Fuchs, B., Bresler, K., and Schiller, J. (2011). Oxidative changes of lipids monitored by MALDI MS. Chem. Phys. Lipids 164, 782-795. doi: 10.1016/j.chemphyslip. 2011.09.006

Gamero-Sandemetrio, E., Gómez-Pastor, R., and Matallana, E. (2014). Antioxidant defense parameters as predictive biomarkers for fermentative capacity of active dried wine yeast. Biotechnol. J. 9, 1055-1064. doi: 10.1002/biot.201300448

Garre, E., Raginel, F., Palacios, A., Julien, A., and Matallana, E. (2010). Oxidative stress responses and lipid peroxidation damage are induced during dehydration in the production of dry active wine yeasts. Int. J. Food Microbiol. 136, 295-303. doi: 10.1016/j.ijfoodmicro.2009.10.018

Gautier, J., Passot, S., Pénicaud, C., Guillemin, H., Cenard, S., Lieben, P., et al. (2013). A low membrane lipid phase transition temperature is associated with a high cryotolerance of Lactobacillus delbrueckii subspecies bulgaricus CFL1. J. Dairy Sci. 96, 5591-5602. doi: 10.3168/jds.2013-6802

Gervais, P., Marechal, P. A., and Molin, P. (1992). Effects of the kinetics of osmotic pressure variation on yeast viability. Biotechnol. Bioeng. 40, 1435-1439. doi: 10.1002/bit.260401119

Guyot, S., Ferret, E., and Gervais, P. (2006). Yeast survival during thermal and osmotic shocks is related to membrane phase change. J. Agric. Food Chem. 54, 8450-8455. doi: 10.1021/jf0620158

Guzmán, E., Mateos-Maroto, A., Ruano, M., Ortega, F., and Rubio, R. G. (2017). Layer-by-Layer polyelectrolyte assemblies for encapsulation and release of active compounds. Adv. Colloid Interface Sci. 249, 290-307. doi: 10.1016/j.cis. 2017.04.009

Hansen, J. M., Go, Y.-M., and Jones, D. P. (2006). Nuclear and mitochondrial compartentation of oxidative stress and redox signaling. Annu. Rev. Pharmacol. Toxicol. 46, 215-234.

Hong, D., Park, M., Yang, S. H., Lee, J., Kim, Y.-G., and Choi, I. S. (2013). Artificial spores: cytoprotective nanoencapsulation of living cells. Trends Biotechnol. 31, 442-447. doi: 10.1016/j.tibtech.2013.05.009

Ishida, K. P., and Griffiths, P. R. (1993). Investigation of polysaccharide adsorption on protein conditioning films by attenuated total reflection infrared spectrometry. J. Colloid Interface Sci. 160, 190-200. doi: 10.1006/jcis.1993. 1383

Kim, B. J., Choi, I. S., and Yang, S. H. (2016). Cytocompatible coating of yeast cells with antimicrobial chitosan through layer-by-layer assembly. Bull. Korean Chem. Soc. 37, 1850-1853. doi: 10.1002/bkcs.10963

Kiprono, S. J., Ullah, M. W., and Yang, G. (2018). Surface engineering of microbial cells: strategies and applications. Eng. Sci. 1, 33-45.

Kong, J., and Yu, S. (2007). Fourier transform infrared spectroscopic analysis of protein secondary structures. Acta Biochim. Biophys. Sin. 39, 549-559. doi: 10.1111/j.1745-7270.2007.00320.x

Lemetais, G., Dupont, S., Beney, L., and Gervais, P. (2012). Air-drying kinetics affect yeast membrane organization and survival. Appl. Microbiol. Biotechnol. 96, 471-480. doi: 10.1007/s00253-012-4014-3

Miller, L. M., and Dumas, P. (2006). Chemical imaging of biological tissue with synchrotron infrared light. Biochim. Biophys. Acta Biomembr. 1758, 846-857. doi: 10.1016/j.bbamem.2006.04.010

Moon, H. C., Han, S., Borges, J., Pesqueira, T., Choi, H., Han, S. Y., et al. (2020). Enzymatically degradable, starch-based layer-by-layer films: application to cytocompatible single-cell nanoencapsulation. Soft Matter. 16, 6063-6071. doi: $10.1039 / \mathrm{d} 0 \mathrm{sm} 00876 \mathrm{a}$

Morgan, C. A., Herman, N., White, P. A., and Vesey, G. (2006). Preservation of micro-organisms by drying; a review. J. Microbiol. Methods 66, 183-193. doi: 10.1016/j.mimet.2006.02.017

Movasaghi, Z., Rehman, S., and Rehman, I. U. (2008). Fourier Transform Infrared (FTIR) Spectroscopy of Biological Tissues. Appl. Spectrosc. Rev. 43:45.

Nguyen, T. D. (2016). Protection de la Levure Saccharomyces cerevisiae Par Un Sustème Biopolymérique Multicouche : Effet Sur Son Activité Métabolique en Réponse Aux Conditions de L'environnement. Ph.D. thesis, AgroSup Dijon, Université Bourgogne-Franche Comté, Dijon.

Nguyen, T. D., Guyot, S., Lherminier, J., Wache, Y., Saurel, R., and Husson, F. (2015). Protection of living yeast cells by micro-organized shells of natural polyelectrolytes. Process Biochem. 50, 1528-1536. doi: 10.1016/j.procbio.2015. 06.003

Nguyen, T. D., Guyot, S., Pénicaud, C., Passot, S., Sandt, C., Fonseca, F., et al. (2017). Understanding the responses of Saccharomyces cerevisiae yeast strain during dehydration processes using synchrotron infrared spectroscopy. Analyst 142, 3620-3628. doi: 10.1039/c7an00257b

Oberg, K. A., Ruysschaert, J.-M., and Goormaghtigh, E. (2004). The optimization of protein secondary structure determination with infrared and circular dichroism spectra. Eur. J. Biochem. 271, 2937-2948. doi: 10.1111/j.1432-1033.2004.04 220.x

Otero, V., Sanches, D., Montagner, C., Vilarigues, M., Carlyle, L., Lopes, J. A., et al. (2014). Characterisation of metal carboxylates by Raman and infrared spectroscopy in works of art. J. Raman Spectrosc. 45, 1197-1206. doi: 10.1002/ jrs. 4520

Palacios, G., and Juárez-López, A. J. (2004). Monhemius, Infrared spectroscopy of metal carboxylates: II. Analysis of $\mathrm{Fe}(\mathrm{III}), \mathrm{Ni}$, and $\mathrm{Zn}$ carboxylate solutions. Hydrometallurgy 72, 139-148. doi: 10.1016/s0304-386x(03)00137-3

Passot, S., Gautier, J., Jamme, F., Cenard, S., Dumas, P., and Fonseca, F. (2015). Understanding the cryotolerance of lactic acid bacteria using combined synchrotron infrared and fluorescence microscopies. Analyst 140, 5920-5928. doi: 10.1039/c5an00654f

Penicaud, C., Landaud, S., Jamme, F., Talbot, P., Bouix, M., Ghorbal, S., et al. (2014). Physiological and biochemical responses of Yarrowia lipolytica to dehydration induced by air-drying and freezing. PLoS One 9:e111138. doi: 10.1371/journal. pone. 0111138

Pereira de Jusus, E., Dolly, A., and Araujo, E. C. (2003). Protection against oxidation during dehydration of yeast. Cell Stress Chaperon. 8, 120-124. 
Saulou, C., Jamme, F., Girbal, L., Maranges, C., Fourquaux, I., Cocaign-Bousquet, M., et al. (2013). Synchrotron FTIR microspectroscopy of Escherichia coli at single-cell scale under silver-induced stress conditions. Anal. Bioanal. Chem. 405, 2685-2697. doi: 10.1007/s00216-013-6725-4

Saulou, C., Jamme, F., Maranges, C., Fourquaux, I., Despax, B., Raynaud, P., et al. (2010). Synchrotron FTIR microspectroscopy of the yeast Saccharomyces cerevisiae after exposure to plasma-deposited nanosilver-containing coating. Anal. Bioanal. Chem. 396, 1441-1450. doi: 10.1007/s00216-0093316-5

Simonin, H., Beney, L., and Gervais, P. (2007). Sequence of occurring damages in yeast plasma membrane during dehydration and rehydration: Mechanisms of cell death. Biochim. Biophys. Acta Biomembr. 1768, 1600-1610. doi: 10.1016/j. bbamem.2007.03.017

Simonin, H., Beney, L., and Gervais, P. (2008). Controlling the membrane fluidity of yeasts during coupled thermal and osmotic treatments. Biotechnol. Bioeng. 100, 325-333. doi: 10.1002/bit.21749
Thomas, M. B., Vaidyanathan, M., Radhakrishnan, K., and Raichur, A. M. (2014). Enhanced viability of probiotic Saccharomyces boulardii encapsulated by layerby-layer approach in $\mathrm{pH}$ responsive chitosan-dextran sulfate polyelectrolytes. J. Food Eng. 136, 1-8. doi: 10.1016/j.jfoodeng.2014.03.015

Conflict of Interest: The authors declare that the research was conducted in the absence of any commercial or financial relationships that could be construed as a potential conflict of interest.

Copyright (C) 2020 Nguyen, Guyot, Pénicaud, Passot, Sandt, Fonseca, Saurel and Husson. This is an open-access article distributed under the terms of the Creative Commons Attribution License (CC BY). The use, distribution or reproduction in other forums is permitted, provided the original author(s) and the copyright owner(s) are credited and that the original publication in this journal is cited, in accordance with accepted academic practice. No use, distribution or reproduction is permitted which does not comply with these terms. 